\title{
Mechanism of luminal ATP activated chloride secretion in a polarized epithelium
}

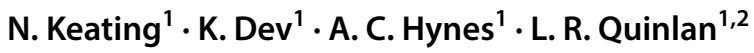

Received: 26 April 2018 / Accepted: 6 June 2018 / Published online: 14 June 2018

(c) The Physiological Society of Japan and Springer Japan KK, part of Springer Nature 2018

\begin{abstract}
There are both secretory and absorptive pathways working in tandem to support ionic movement driving fluid secretion across epithelia. The mechanisms exerting control of fluid secretion in the oviduct is yet to be fully determined. This study explored the role of apical or luminal extracellular ATP (ATPe)-stimulated ion transport in an oviduct epithelium model, using the Ussing chamber short-circuit current (Isc) technique. Basal Isc in oviduct epithelium in response to apical ATPe comprises both chloride secretion and sodium absorption and has distinct temporal phases. A rapid transient peak followed by a sustained small increase above baseline. Both phases of the apical ATPe Isc response are sensitive to anion $\left(\mathrm{HCO}_{3}{ }^{-}\right.$, $\left.\mathrm{Cl}^{-}\right)$and cation $\left(\mathrm{Na}^{+}\right)$replacement. Additionally, the role of apical chloride channels, basolateral potassium channels and intracellular calcium in supporting the peak Isc current was confirmed. The role of ATP breakdown to adenosine resulting in the activation of $\mathrm{P} 2$ receptors was supported by examining the effects of non-hydrolyzable forms of ATP. A P2YR2 potency profile of ATP $=\mathrm{UTP}>$ ADP was generated for the apical membrane, suggesting the involvement of the P2YR2 subtype of purinoceptor. A P2X potency profile of ATP $=2$ MeSATP $>$ alpha,beta-meATP $>$ BzATP was also generated for the apical membrane. In conclusion, these results provide strong evidence that purinergic activation of apical P2YR2 promotes chloride secretion and is thus an important factor in fluid formation by the oviduct.
\end{abstract}

Keywords Oviduct epithelium · Chloride secretion · ATP · Calcium signaling · Potassium channels $\cdot$ Chloride channels · Purinoceptors

\section{Introduction}

The general principle of fluid formation and fluid secretion is secondary to and driven by the active transport of ions across a tight epithelial barrier. Previously we have shown that chloride is the predominant ion responsible for driving fluid secretion in the oviduct [1]. In this model, chloride secretion is followed by the paracellular movement of sodium across the epithelial layer. The resulting luminal accumulation of sodium chloride produces an osmotic gradient that generates a force, pulling fluid into the lumen of the tube. Fluid secretion by the lining of the oviduct ensures the appropriate and essential environment for gamete maturation and transport,

$\triangle$ L. R. Quinlan

leo.quinlan@nuigalway.ie

1 Physiology, School of Medicine, National University of Ireland, Galway, University Road, Galway, Ireland

2 CÚRAM, Centre for Research in Medical Devices, NUIGalway, University Road, Galway, Ireland fertilization, and supports the early stages of embryo development. The composition of this fluid has been well documented for a number of years $[2,3]$ while the mechanistic interplay underlying fluid formation is surprisingly slow to be understood despite some recent advances [1, 4].

Fluid secretion in the oviduct is an essential component of normal oviduct physiology; the fluid acts primarily to hydrate and protect the luminal surface, additionally acting to provide an appropriate ionic environment to facilitate healthy reproductive function [5-7]. In disease states such as pelvic inflammatory disease and cystic fibrosis, dysregulated fluid formation occurs, leading to reduced fertility in vivo, but can also compromise IVF efforts in women affected [8]. Despite an increased level of understanding, there remains both a knowledge deficit and a fundamental unmet clinical need to fully elucidate the basis and regulation of fluid secretory processes in the oviduct.

Previously our group has shown that chloride secretion in the oviduct is maintained by a number of ion transporters and channels in the luminal domain of the epithelium. 
Chloride secretion in the oviduct occurs predominantly through calcium activated $\mathrm{Cl}^{-}$channels $(\mathrm{CaCC})$ and cAMP activated CFTR $\mathrm{Cl}^{-}$channels. We have reported that chloride secretion is the mainstay of basal and extracellular ATP (ATPe)-stimulated ionic currents across bovine oviduct epithelium [1]. More recently, we have demonstrated the functional presence of potassium channels in the basolateral domain of a polarized oviductal epithelium model [4]. These potassium channels are active under basal conditions supporting both sodium absorption and chloride secretion. These channels provide a driving force for the rapid transient increase in chloride secretion following basolateral stimulation with extracellular ATP (ATPe) [4]. Additionally, we have shown that ATPe directly activates a P2Y2, G-proteincoupled receptor on the basolateral membrane which promotes chloride secretion through calcium dependent $(\mathrm{CaCC})$ and independent mechanisms (CFTR) [4].

A variety of stimuli are capable of causing ATP release from epithelial cells, including hormonal, inflammatory or mechanical stimuli. Hormonal stimulation across the normal reproductive cycle may affect ATP release and subsequently fine tune fluid formation. In the setting of inflammation, for example, the release of ATP may play an important role in the reproductive tract. ATPe could be involved in initiating non-specific defense mechanisms whereby activation of chloride secretion, and the subsequent movement of water into the lumen, would help flush noxious substances from the lumen similar to ciliary clearance seen in the airways. The mechanical presence of the unfertilized ovum may stimulate ATP release, thereby providing a feedforward mechanism to generate the appropriate environment for fertilization and early development. Regardless of the trigger of ATP release, the paracrine and autocrine actions of ATP on the apical domain of the oviduct remain unknown. This study reports the characterization of apical domain responses to ATPe and investigates the receptors and channels associated with chloride secretion and sodium absorption across the oviduct epithelium.

\section{Materials and methods}

\section{Materials}

All chemicals, unless otherwise stated, were purchased from Sigma Aldrich. All general cell culture reagents were purchased from Sigma, with the exceptions of pancreatin, fungizone and fetal calf serum (FCS), which were purchased from Gibco.

\section{Cell culture}

Bovine oviducts at various stages of the estrous cycle were removed from cattle at a local abattoir within 5 min of slaughter. Epithelial cells were isolated according to the methods previously described for the isolation of rat uterine epithelium $[6,9]$. The oviducts were immediately separated from connective tissue, fat and major blood vessels and the fimbriae removed. Oviducts were washed in a $\mathrm{Ca}^{2+}$ and $\mathrm{Mg}^{2+}$-free Hanks balanced salt solution (HBSS). Each oviduct was opened longitudinally to expose the epithelia and cut into $1-\mathrm{cm}$ segments and incubated with $0.5 \%$ type I trypsin and $2.7 \%$ (w:v) pancreatin for $1 \mathrm{~h}$ at $4{ }^{\circ} \mathrm{C}$ followed by $1 \mathrm{~h}$ at room temperature. The cellular suspension was vortexed for $30 \mathrm{~s}$, followed by centrifugation at $500 \times \mathrm{g}$ for 4 min. The resultant pellet was washed 3 times in $\mathrm{Ca}^{2+}$ and $\mathrm{Mg}^{2+}$-free HBSS. After washing, cells were re-suspended in pre-warmed, pre-gassed culture medium.

The culture medium consisted of the nutrient mixture F12 Hams plus Dulbecco Modified Eagle medium in a $1: 1$ ratio $(\mathrm{v} / \mathrm{v})$. The final culture medium also had the following additions: $0.1 \%$ bovine serum albumin, $150 \mathrm{IU} / \mathrm{ml}$ penicillin $\mathrm{G}, 150 \mu \mathrm{g} / \mathrm{ml}$ streptomycin sulphate, $1.25 \mu \mathrm{g} / \mathrm{ml}$ fungizone, $2 \mathrm{mM}$ L-glutamine and 10\% FCS. Isolated cells from multiple oviducts were pooled and plated at a density of approx. $1 \times 10^{6}$ cells $/ \mathrm{ml}$.

\section{Measurement of short circuit current (Isc)}

Cells were plated on snapwell inserts with a growth area of $12 \mathrm{~mm}^{2}$ (Corning Costar), monolayers achieved confluence after approx. 4 days in culture. A volume of $250 \mu \mathrm{l}$ of the cell suspension was added on top of the inserts and $4 \mathrm{ml}$ of culture medium added underneath. The cells were incubated in a humidified incubator at $37{ }^{\circ} \mathrm{C}$ and gassed with $5 \% \mathrm{CO}_{2}$ in air. The medium above and below the filters was replaced every $48 \mathrm{~h}$. The development of an appreciable trans-epithelial resistance (Rte) across these filters was used an indicator of the formation of a polarized monolayer, this was measured daily using chopstick electrodes (EVOM voltage meter, World Precision Instruments, Inc., Sarasota, FL). All monolayers were used in a window of 6-7 days in culture and were only considered for use in electrophysiological studies once Rte $\geq 1 \mathrm{k} \Omega \mathrm{cm}^{2}$. Filters were placed in modified Ussing chambers (World Precision Instruments, Inc., Sarasota, FL), with both surfaces of the cells bathed with normal Krebs-Ringer bicarbonate solution and gassed with $95 \% \mathrm{O}_{2} / 5 \% \mathrm{CO}_{2}$, at $37.5{ }^{\circ} \mathrm{C}$. The normal Krebs-Ringer bicarbonate solution contained:

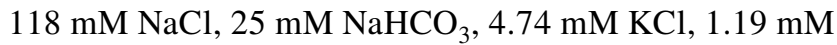


$\mathrm{MgSO}_{4}, 1.17 \mathrm{mM} \mathrm{KH} \mathrm{PO}_{4}, 1.17 \mathrm{mM} \mathrm{CaCl}_{2}$ and $1 \mathrm{mM}$ glucose, gassed with $95 \% \mathrm{O}_{2} / 5 \% \mathrm{CO}_{2}$.

The spontaneous transmembrane potential was measured using a voltage clamp amplifier (DVC 1000, World Precision Instruments, Inc., Sarasota, FL) and clamped to $0 \mathrm{mV}$ by the application of a short circuit current (Isc). The output from the amplifier was digitized using a PowerLab (AD Instruments) and analyzed using LabChart software (AD Instruments). Cells were allowed to equilibrate for $20 \mathrm{~min}$ to achieve a stable Isc before beginning an experiment. ATP was prepared in normal Krebs-Ringer and added to the experimental chamber in $100-\mu 1$ aliquots. All other agents/antagonists were prepared in DMSO (maximum final volume of $0.1 \%$ ). Where ion channel inhibitors were used, the cells were incubated in the presence of the inhibitor for 10 min prior to ATPe addition. In this case all results were expressed as a percentage of the control ATPe response.

\section{Experimental design}

Results are expressed as mean \pm SEM. Each cell isolation is an experimental block and each well/monolayer a replicate within the block. Thus, each block contained cells pooled from two or more animals. For all treatments, $n$ indicates the number of wells/monolayers examined and, in all cases, replicates were examined over two or more experimental blocks. In all cases each treatment was paired with a vehicle control. The vehicle control was found to have no effect on basal or ATPe-stimulated Isc responses. All results were examined statistically by analysis of variance and, where appropriate, the Bonnferroni/Dunn post hoc test was used. $P$ values $<0.05$ were considered to be statistically significant.

\section{Results}

\section{The effect of apically applied ATPe on short circuit response}

Previously we have shown that over the range 1-2000 $\mu \mathrm{M}$ ATPe, $100 \mu \mathrm{M}$ generates approximately an $80 \%$ maximal response, so that concentration was used throughout this study [1]. The application of ATPe $(100 \mu \mathrm{M})$ to the apical surface of the epithelial cell monolayer induced a rapid and transient increase in current of $28.82 \pm 1.66 \mu \mathrm{A} / \mathrm{cm}^{2}$ (Fig. 1a), with no discernible latency and reached a peak current in $1.65 \pm 0.07 \mathrm{~s}$, followed by a rapid decrease in current. However, unlike the typical basolateral response for this tissue [1, 4], the Isc did not return back to baseline, but instead maintained a sustained current of $1.91 \pm 0.115 \mu \mathrm{A} / \mathrm{cm}^{2}(n=18)$ above baseline. To investigate any desensitization of the observed apical ATP response, ATPe $(100 \mu \mathrm{M})$ was added apically, followed 5 min later by a second equimolar ATPe challenge. This resulted in a $90 \%$ reduction in Isc compared to the initial Isc response (Fig. 1b). Washing the monolayer between ATPe treatments facilitated a recovery of up to $75 \%$ of a normal response, illustrating partial desensitization (data not shown). When Amiloride $(100 \mu \mathrm{M})$ was added apically, $10 \mathrm{~min}$ prior to ATPe, it did not significantly affect the initial Isc peak. This indicates that the initial transient increase in Isc is likely to be due to an anion secretory current component, based on the direction of the measured current. However, the sustained current remained slightly higher in the presence of amiloride $(P<0.022)$. These data are consistent with ATP having a dual effect in inhibiting the amiloride sensitive Isc component and stimulating an anion secretory component (Fig. 1c).

\section{Effect of ionic substitution on the apical ATPe response}

Ionic substitution experiments revealed that the ATPeinduced increase in Isc was due to $\mathrm{Cl}^{-}$secretion or $\mathrm{HCO}_{3}{ }^{-}$secretion or both, based on replacing extracellular chloride ions with gluconate on both sides of the epithelial monolayer and/or substituting $\mathrm{HCO}_{3}{ }^{-}$ions with HEPES. Removal of either $\mathrm{Cl}^{-}(P<0.001)$ or $\mathrm{HCO}_{3}{ }^{-}$significantly reduced $(P<0.003)$ both the transient and sustained ATPeinduced Isc response (Fig. 2a). The removal of both anions $(P<0.0001)$ decreased the ATP-induced Isc by $70 \%$ indicating that the major fraction of the peak response represents anion secretion. The removal of both anions $(P<0.001)$ also significantly decreased the sustained ATP-induced Isc response; however, this was not significantly different to the ATP response in $\mathrm{Cl}^{-}$free solution only. Bilateral replacement of sodium with choline resulted in the complete abolition of the normal baseline Isc and a substantial inhibition of the normal transient and sustained responses $(P<0.0001)$ (Fig. 2b). Basolateral replacement of sodium with choline did not alter the baseline Isc; however, it significantly reduced the peak and sustained ATPe responses $(P<0.005)$. Thus, it appears that the ATPe-stimulated Isc is dependent on basolateral $\mathrm{Na}^{+}$. The transient increase in Isc in response to apical ATPe is largely independent of apical $\mathrm{Na}^{+}$but is strongly dependent on basolateral $\mathrm{Na}^{+}$which probably reflects the sodium dependency of basolateral $\mathrm{Na}^{+}$-coupled co-transporters, needed to accumulate $\mathrm{Cl}^{-}$and bicarbonate inside oviductal epithelial cells. The ATP-induced sustained increase in current is dependent on both apical and basolateral $\mathrm{Na}^{+}$.

\section{Identifying the channel(s) involved in the apical ATPe-induced anion secretion and the role of calcium}

In the presence of amiloride (applied apically for $10 \mathrm{~min}$ ) specific $\mathrm{Cl}^{-}$or $\mathrm{K}^{+}$channel blockers were examined for 

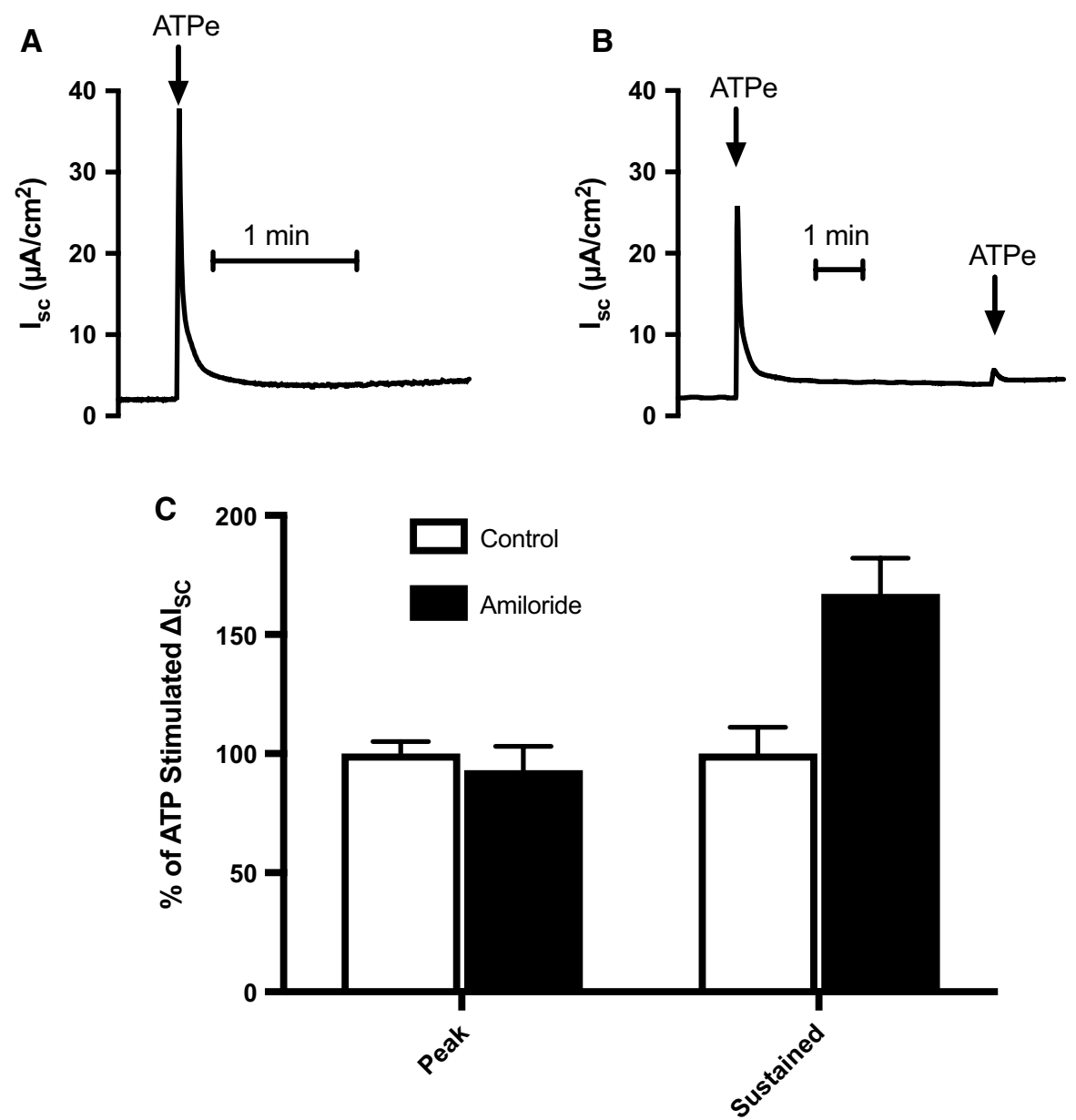

Fig. 1 Effect of apical ATPe on oviduct Isc. A Representative trace of Isc across the oviduct epithelium following apical application of ATP $(100 \mu \mathrm{M})$. B Representative trace of Isc across the oviduct epithelium

an effect on the ATPe current. Each $\mathrm{Cl}^{-}$channel blocker resulted in significant inhibition of the peak ATPe-induced increase in Isc (NPPB, $P<0.009$; glybenclamide, $P<0.001$; NFA, $P<0.0001$ ) (Fig. 3a). The inhibitory effects of both glybenclamide, and NFA suggests that both $\mathrm{Ca}^{2+}$-activated $\mathrm{Cl}^{-}$channels and CFTR $\mathrm{Cl}^{-}$channels may be involved in the peak response induced by apical ATPe. In contrast, the sustained response remained almost unaffected by each of the $\mathrm{Cl}^{-}$channel blockers. NPPB was the only inhibitor to exert a significant inhibitory effect on the sustained ATP response $(P<0.009)$. Previously, we have shown the importance of $\mathrm{Ca}^{2+}$ activated $\mathrm{K}^{+}$channels in the basolateral ATPe-induced chloride secretory response in oviduct epithelial cells. To investigate a similar role for this type of channel in the apical ATP response we pretreated the basolateral side of the cells with tetrapentyl ammonium (TPeA) $(100 \mu \mathrm{M})$ for $10 \mathrm{~min}$ before the addition of ATPe apically. Amiloride was also present to prevent contamination of anion secretion with absorptive sodium current. The treatment regimen almost showing the effect of repeated application of apical ATPe. C Effect of amiloride on the ATPe-induced Isc response. Values are mean \pm SEM for at least 4 replicates

completely abolished the ATPe-induced response (transient response, $P<0.0001$; sustained response, $P<0.0003$, Fig. 3a), suggesting that the $\mathrm{Ca}^{2+}$-activated $\mathrm{K}^{+}$channels may play an important role in the apical ATP response.

Furthermore, we previously demonstrated that basolateral ATPe-induced chloride secretion in oviduct epithelial cells is dependent on intracellular $\mathrm{Ca}^{2+}$ and the release of $\mathrm{Ca}^{2+}$ from intracellular stores. Pretreatment of the cells with thapsigargin (Thaps), in the absence of amiloride, abolished the normal ATPe-induced Isc response $(P<0.0001$, Fig. $3 \mathrm{~b}$. Pretreatment with Thaps, in the presence of apical amiloride, evoked a similar inhibitory reaction, down-regulating the typical response observed for apical ATPe significantly $(P<0.0003)$. These results suggest that the transient apical ATPe-induced increase in Isc is dependent on $\mathrm{Ca}^{2+}$ and the release of $\mathrm{Ca}^{2+}$ from thapsigargin-sensitive stores. The sustained current, however, remained unaffected, which suggests that the sustained response to ATPe is generated by a $\mathrm{Ca}^{2+}$-independent mechanism. In the absence of amiloride, 

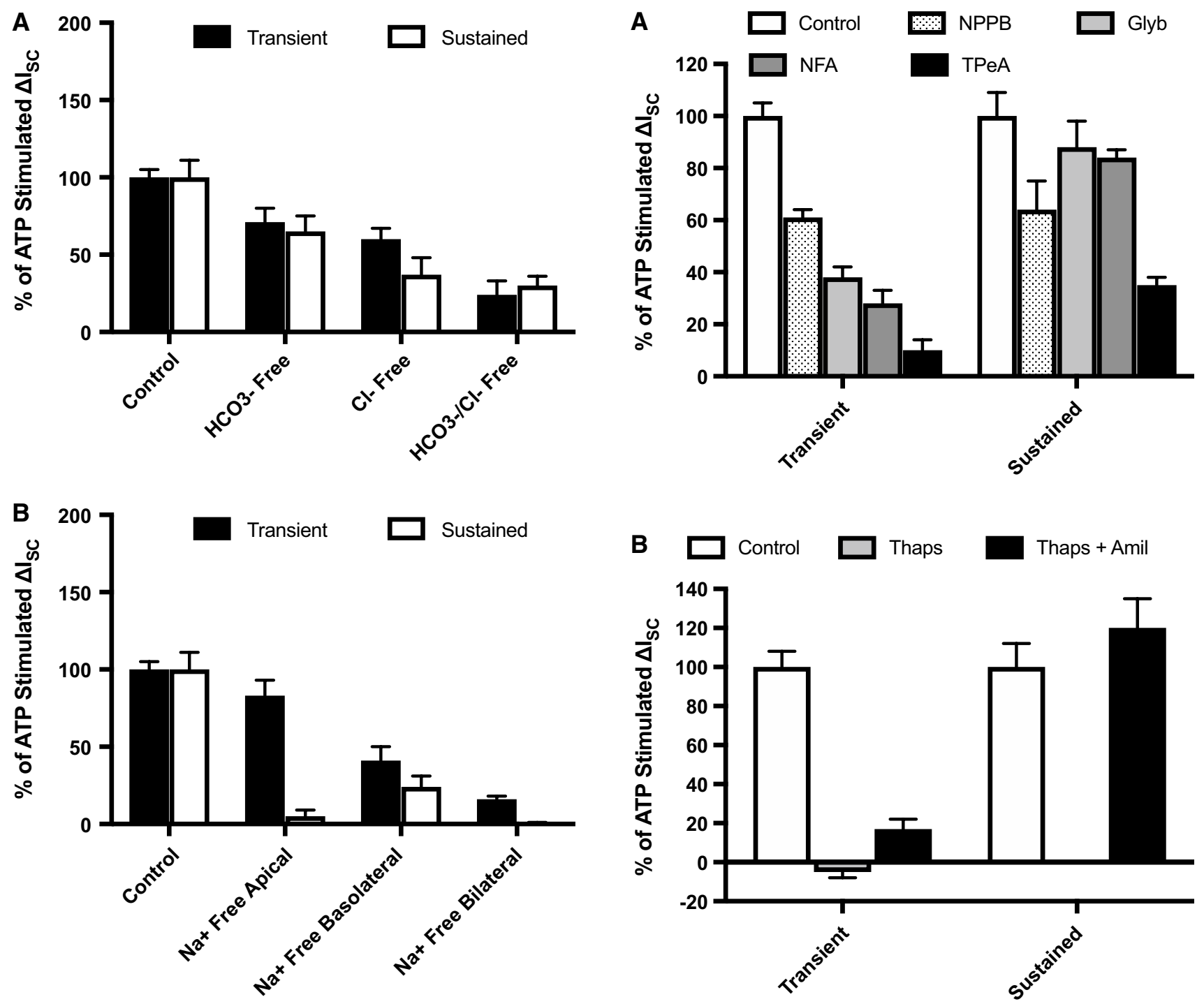

Fig. 2 Effect of ionic substitution on phases of Isc response to apical ATPe. A Effect of anion substitution. B Effect of sodium substitution. Values are mean \pm SEM for at least 4 replicates

however, the sustained ATPe response was significantly inhibited by pretreatment with thapsigargin $(P<0.0001)$. This may be due to the concomitant inhibition of $\mathrm{Na}^{+}$channels induced by ATPe as suggested earlier, thereby negating any positive anion secretory current generated.

\section{Effect of forskolin on basal Isc and ATP-stimulated Isc}

For many epithelia sustained anion secretion induced by various agonists is attributable to production of intracellular cAMP through the activation of adenylate cyclase [10]. In this study the addition of $10 \mu \mathrm{M}$ forskolin evoked a rise in Isc that peaked at $3.21 \pm 0.33 \mu \mathrm{A} / \mathrm{cm}^{2}$ and then decreased slightly but remained at a sustained level of

Fig. 3 Role of ion channels and calcium on apical ATPe Isc. A Effect of chloride channel blockers NPPB $(500 \mu \mathrm{M})$, glybenclamide $(100 \mu \mathrm{M})$ and NFA $(100 \mu \mathrm{M})$ and calcium activated potassium channel blocker TPeA $(100 \mu \mathrm{M})$, on apical ATPe $\mathrm{I}_{\mathrm{SC}}$ responses. Values are mean \pm SEM for at least 3 replicates. B Effect of thapsigargin on the apical ATPe $I_{\mathrm{SC}}$ response in the presence and absence of amiloride. Values are mean \pm SEM for at least 4 replicates

$2.11 \pm 0.19 \mu \mathrm{A} / \mathrm{cm}^{2}$ above baseline (Fig. 4a). Addition of ATPe resulted in a transient increase in current but no additional sustained component as normally found with apical application of ATPe (Fig. 4b). In contrast, when monolayers were pretreated with ATP $(100 \mu \mathrm{M})$ for $5 \mathrm{~min}$, forskolin failed to exert any significant effect on the Isc (data not shown). These results indicate that forskolin and ATPe together stimulate the same sustained current as forskolin alone. The lack of an additive effect suggests that apical ATP may be activating a cAMP-dependent anion current as part of the ATP response. 

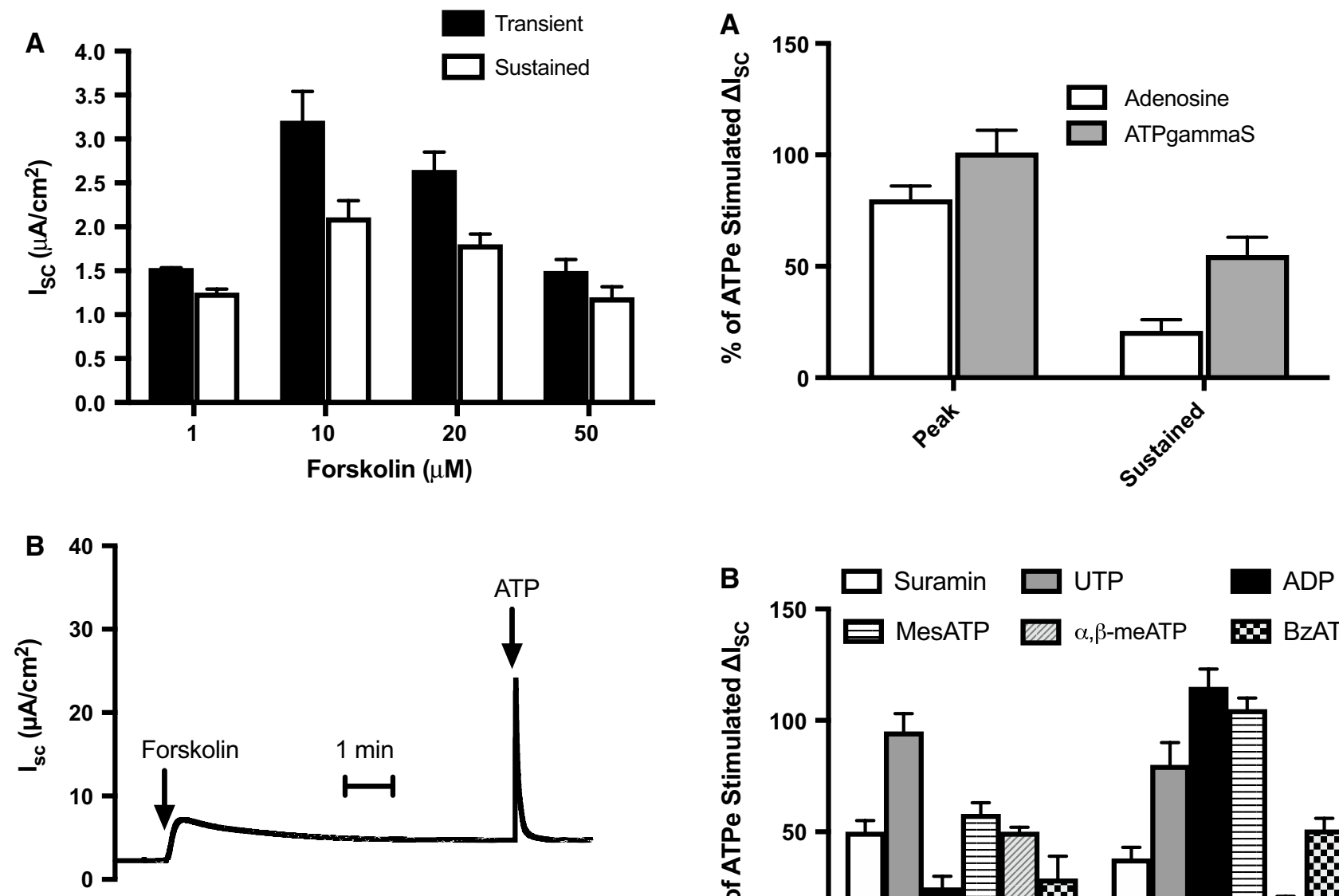

Fig. 4 Effect of apically applied forskolin on $\mathrm{I}_{\mathrm{SC}}$. A Dose response relationship for the effect of forskolin on the $\mathrm{I}_{\mathrm{SC}}$. Values are mean \pm SEM for at least 4 replicates. B Representative traces (at least 4 replicates) showing the $\mathrm{I}_{\mathrm{SC}}$ response to ATP after forskolin application

\section{Effect of adenosine and ATP analogs on basal Isc and ATP-stimulated IsC}

Extracellular ATP is known to be catabolized to ADP, AMP or adenosine by various ectoenzymes [11-13]. Stimulation of $\mathrm{A} 2$ receptors by adenosine has been shown to activate adenylate cyclase [14], which may explain the sustained component of the current induced by ATPe. Addition of adenosine $(100 \mu \mathrm{M})$ caused a rapid, but modest increase in Isc (compared to ATPe) current to $7.46 \pm 0.86 \mu \mathrm{A} / \mathrm{cm}^{2}$ that declined to a sustained level of $4.31 \pm 0.38 \mu \mathrm{A} / \mathrm{cm}^{2}$ above baseline. Pretreatment of the monolayers with ATPe resulted in a significant reduction in the sustained current generated by adenosine (Fig. 5a), suggesting that the sustained component of the ATPe response may be due to activation of the same signaling pathway as adenosine.

To investigate the possibility of ATPe degradation in the Isc observed, the effect of the metabolically stable analog, ATPgammaS on the Isc was investigated. The addition of ATPgammaS $(100 \mu \mathrm{M})$ to the apical face of the epithelial

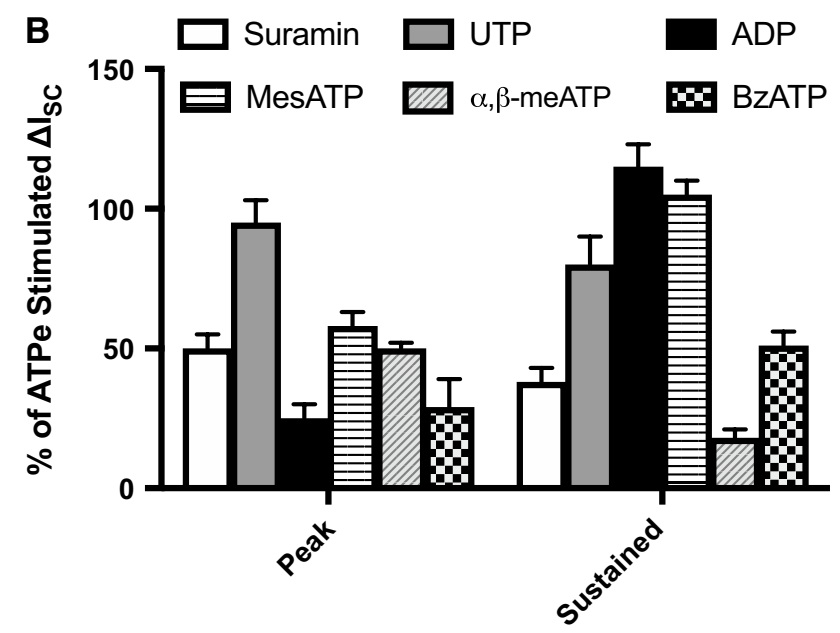

Fig. 5 A Effect of adenosine pretreatment on the apical ATP response and effect of ATPgammaS on $\mathrm{I}_{\mathrm{SC}}$. Values are mean \pm SEM for at least 4 replicates. B Effect of suramin and selected P2YR and P2XR receptor antagonists on the apical ATPe response. Values are mean \pm SEM for at least 4 replicates

monolayer produced a similar transient response to ATPe (Fig. 5a). However, the sustained response was significantly less than that of ATPe $(P<0.008)$, consistent with the possibility that ATPe may be degraded to adenosine or some other form of adenine nucleotide which in turn may be partially responsible for the sustained component of the ATPe response.

To assess the involvement of purinoceptors in the apical ATP-induced Isc response, monolayers were pretreated with suramin $(500 \mu \mathrm{M})$ prior to the application of ATPe. Under these conditions a 50\% reduction in the ATP response was observed, supporting a role for $\mathrm{P} 2$ purinoceptors in this response $(P<0.001)$ (Fig. 5b). In order to determine the receptor subtypes involved in the apical ATP response, the effect of a panel of different P2Y agonists (ATP, UTP and 
ADP) were tested to assess their ability to activate an Isc response. A dose of $100 \mu \mathrm{M}$ was used for each of the agonists and a potency profile was determined. UTP had a similar effect to ATPe $(P<0.78)$ on both the peak and sustained components of the apical response (Fig. 5b). ADP induced a significantly lower peak current, but a larger sustained current compared to that of ATP. Overall comparison of the peak Isc produced by the tested nucleotides gives a rank order of potency of: ATP $=\mathrm{UTP}>\mathrm{ADP}$. This is most consistent with the P2YR2 subclass of purinoceptor. To investigate the involvement of $\mathrm{P} 2 \mathrm{X}$ purinoceptors, the effects of the P2X agonists ATP, 2MeSATP, alpha, beta-meATP and BzATP on the Isc were examined and a potency profile determined. All of the agents tested yielded a response of similar pattern to ATP. Comparison of the peak Isc produced by the $\mathrm{P} 2 \mathrm{X}$ agonists gives a rank order of potency of ATP $>$ 2MeSATP = alpha, beta-meATP $>$ BzATP (Fig. 5b). This profile is not consistent with any one $\mathrm{P} 2 \mathrm{X}$ receptor subtype, indicating the presence of multiple $\mathrm{P} 2 \mathrm{X}$ purinoceptors on the apical face of oviduct epithelial cells. The sustained current induced by $2 \mathrm{MeSATP}$ was not significantly different to that of ATP; however, that of BzATP was significantly lower. Alpha, beta-meATP, however, produced only a minimal increase in sustained current and this may be due to the fact that alpha,beta-meATP is a metabolically stable
ATP analog, therefore it is not susceptible to breakdown to adenosine or other adenine nucleotides.

\section{Cross-desensitization of the apical ATP response}

To examine the possibility that ATPe may be exerting its effects via $\mathrm{P} 2 \mathrm{X}$ receptors present on the apical membrane and not the proposed P2YR2 receptor, a cross-desensitization experiment was performed. Alpha,beta-meATP is a relatively potent agonist at P2XR1 and P2XR3 and a weak partial agonist or inactive at homomeric P2XR2 and P2XR47. To date, there is no evidence that alpha,beta-meATP recognizes P2Y receptors to any degree [15]. Apical alpha,betameATP-induced a peak increase in Isc of $20.9 \pm 1.4 \mu \mathrm{A} / \mathrm{cm}^{2}$, and subsequent ATPe exposure resulted in a large peak increase in Isc of $32.6 \pm 4.2 \mu \mathrm{A} / \mathrm{cm}^{2}$, which was not significantly different from the control ATPe response $(35.7 \pm 1.6$ $\mu \mathrm{A} / \mathrm{cm}^{2}$ ) (Fig. 6a). This suggests that alpha,beta-meATP and ATPe activate separate distinct receptor subtypes. Thus, while the evidence suggests the presence of functional P2X receptors on the apical membrane, the apical ATPe response is more likely due to activation of a P2Y receptor subtype. Cross-desensitization experiments between apical ATP $(100 \mu \mathrm{M})$ and apical UTP $(100 \mu \mathrm{M})$ were also performed in this study, using the same protocol, to investigate any
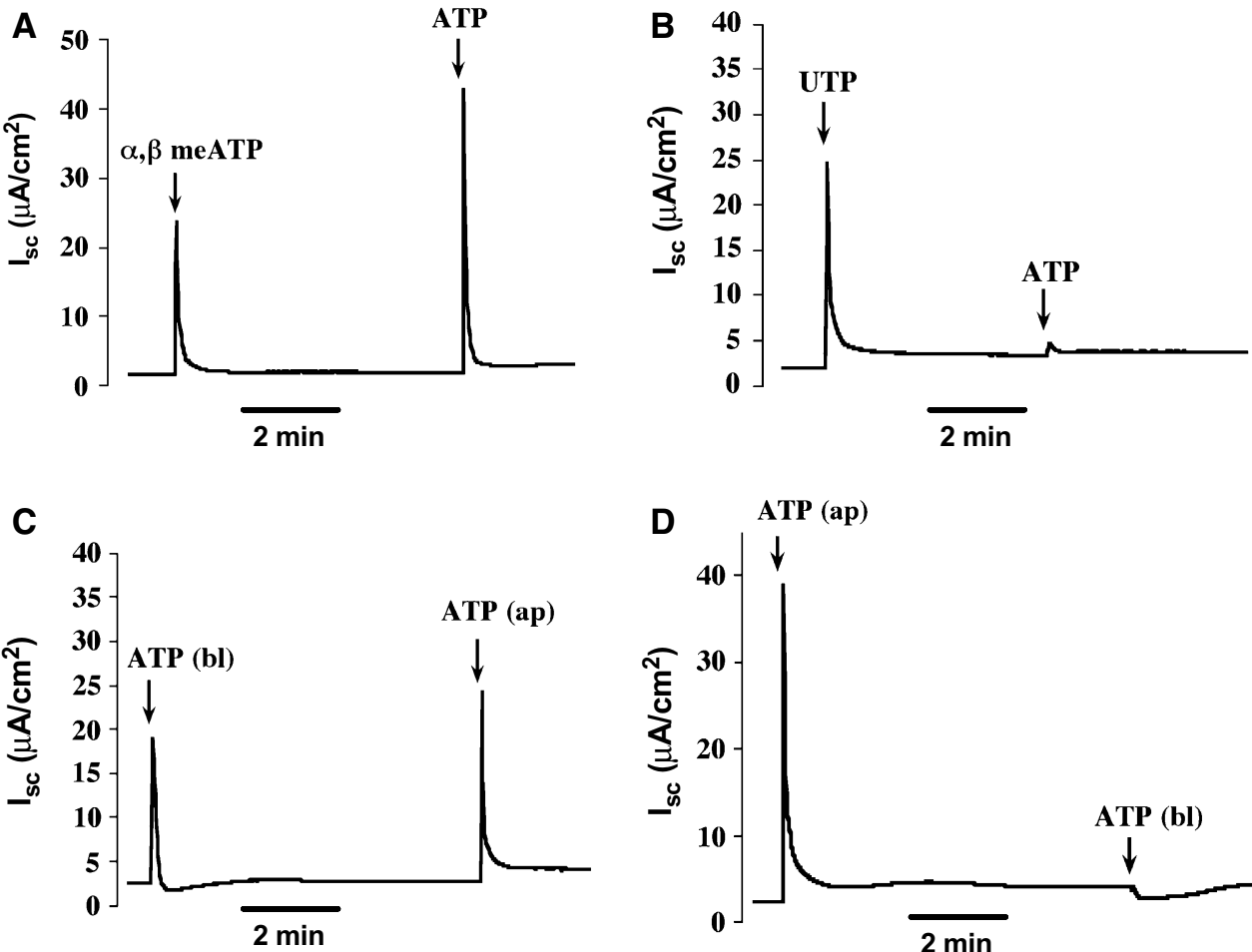

Fig. 6 Representative traces (at least 4 replicates) showing $\mathbf{A}$ the effect of alpha,beta-meATP followed by apical ATPe. B Effect of apical UTP followed by apical ATPe. C Effect of apical ATP following

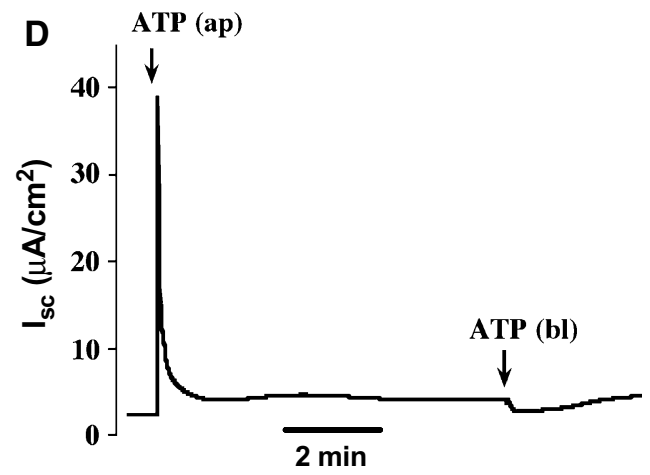

pre-stimulation with basolateral ATP. D Effect of basolateral ATP following pre-stimulation with apical ATPe 
desensitization of the ATP response to the P2Y-specific agonist UTP. Apical UTP induced a transient increase in Isc of $22.7 \pm 0.9 \mu \mathrm{A} / \mathrm{cm}^{2}$. Subsequent ATP exposure failed to produce the normal ATP response, with only a very small increase in Isc observed $\left(2.1 \pm 0.6 \mu \mathrm{A} / \mathrm{cm}^{2}\right)$ (Fig. 6b). This suggests that UTP and ATP activate the same receptor subtype, most likely P2YR2.

The potential interactions between apical and basolateral purinoceptors were also explored by stimulating the apical side of the epithelial cells with ATP $(100 \mu \mathrm{M})$, followed 10 min later by basolateral ATP $(100 \mu \mathrm{M})$. A second experiment was then performed in which the sequence of additions was reversed. Apical ATPe normally induced an increase in Isc of the order of $34.4 \pm 1.1 \mu \mathrm{A} / \mathrm{cm}^{2}$. However, following pre-stimulation with basolateral ATPe, apical ATPe-induced a smaller, but substantial, increase in Isc of $20.8 \pm 1.1 \mu \mathrm{A} / \mathrm{cm}^{2}$ (Fig. 6c). Thus, pretreatment with basolateral ATPe inhibited the anion secretory response to apical ATPe challenge by approximately $40 \%$. To investigate any similar inhibition of the basolateral ATPe response by apical ATPe pretreatment, the sequence of addition was reversed. Basolateral ATPe normally induced an increase in Isc of the order of $17.2 \pm 1.56 \mu \mathrm{A} / \mathrm{cm}^{2}$. However, following prestimulation with apical ATPe, basolateral ATPe challenge failed to increase the Isc (Fig. 6d). Thus, pretreatment with apical ATPe completely abolished the chloride secretory response to basolateral ATPe. A similar effect was observed with UTP application (data not shown). Pre-stimulation of the cells with apical UTP completely abolished the basolateral UTP response. However, when the cells were prestimulated with basolateral UTP, a substantial stimulation of current in response to apical UTP remained, albeit at a reduced level. These results indicate that significant crosstalk between apical and basolateral purinoceptors exists in oviduct epithelial cells.

\section{Discussion}

In this study we have demonstrated that apical ATPe activates a rapid (amiloride insensitive) transient increase in anion secretion in oviduct epithelial cells, followed by a small (amiloride sensitive) sustained current increased above baseline (Fig. 1c), similar to other epithelial cell types [16, 17]. When extracellular $\mathrm{Cl}^{-}$or $\mathrm{HCO}_{3}^{-}$was removed, alone or in parallel, the ATPe-induced response was reduced by 40, 30 and 70\% respectively (Fig. 2). This anion-mediated transient Isc response was also highly dependent on extracellular $\mathrm{Na}^{+}$, in particular basolateral $\mathrm{Na}^{+}$(Fig. 2b), which suggests the presence of a $\mathrm{Na}^{+}$-coupled transporter such as $\mathrm{Na}^{+} / \mathrm{HCO}_{3}{ }^{-}$exchanger to accumulate $\mathrm{HCO}_{3}{ }^{-}$in the cell, along with the $\mathrm{Na}^{+} / \mathrm{K}^{+} / 2 \mathrm{Cl}^{-}$co-transporter to accumulate $\mathrm{Cl}^{-}$, on the basolateral membrane. The dependence of the sustained component on apical $\mathrm{Na}^{+}$is less easily explained but is likely to reflect the inhibition of an apically located $\mathrm{Na}^{+} / \mathrm{H}^{+}$exchanger under sodium-free conditions, which would normally be responsible for $\mathrm{H}^{+}$efflux to achieve maximum $\mathrm{HCO}_{3}{ }^{-}$accumulation [18]. $\mathrm{HCO}_{3}{ }^{-}$extrusion into the uterine lumen has been demonstrated to involve CFTR [19]. Also, since CFTR has been shown to be expressed at high levels in the oviduct [20], it is a likely candidate for the establishment of a high $\mathrm{HCO}_{3}{ }^{-}$content in the oviduct and is supported by the fact that the anion secretory current was drastically reduced in the presence of the CFTR inhibitor, glybenclamide (Fig. 3a). Previously, we have shown that $\mathrm{CaCC}$ are primarily responsible for chloride secretion in response to basolateral ATPe $[1,4]$. However, $\mathrm{CaCC}$ have also been shown to play a role in $\mathrm{HCO}_{3}{ }^{-}$secretion in other epithelia [21,22], therefore we cannot exclude a similar role for $\mathrm{CaCC}$ here. The effect of ATPe on $\mathrm{HCO}_{3}{ }^{-}$secretion in the oviduct is novel and interesting and suggests a potentially important role for ATPe in the generation of the high $\mathrm{HCO}_{3}{ }^{-}$content of the oviduct which is essential for normal reproductive function.

In the presence of thapsigargin, the transient apical ATPe response is completely abolished. illustrating the importance of thapsigargin-sensitive stores in the transient apical ATPe-induced Isc. The sustained component, however, is preserved, which suggests that it is generated by a $\mathrm{Ca}^{2+}$ independent mechanism (Fig. 3b). Interestingly, this effect is only observed in the presence of amiloride and may show that ATPe can exert an inhibitory effect on $\mathrm{Na}^{+}$absorption, thereby reducing the sustained Isc. The increase in $\mathrm{Ca}^{2+}$ in response to apical ATPe is likely to have a dual role in the oviduct. Firstly, as with the basolateral ATPe response, it is involved in activating CaCCs. Secondly, given the substantial inhibition of the apical ATPe Isc response in the presence of TPeA (Fig. 3a), the increase in $\mathrm{Ca}^{2+}$ by apical ATP also acts to stimulate basolateral $\mathrm{Ca}^{2+}$-activated $\mathrm{K}^{+}$ channels, which are essential in providing the driving force for anion secretion through CFTR.

The sustained component of the apical ATPe Isc is likely to involve a cAMP-dependent mechanism. The reasons for this conclusion are twofold. Firstly, as in most secretory epithelia studied, sustained activations in Isc in response to various agonists, including ATPe and forskolin have been attributed to cAMP-dependent activation in ion transport $[10,23]$. Also, in our study, the sustained current was completely abolished following pretreatment with forskolin or adenosine, agonists known to affect cAMP levels. It is also possible that ATPe degradation to adenosine or other nucleotide products on the apical membrane by nucleosidases might occur and may be responsible for generating the sustained current. The observation that the non-hydrolyzable analogs of ATP, ATPgammaS and alpha,beta-meATP exerted much smaller sustained increases in current in this 
Fig. 7 Proposed model of apical ATPe-induced chloride secretion

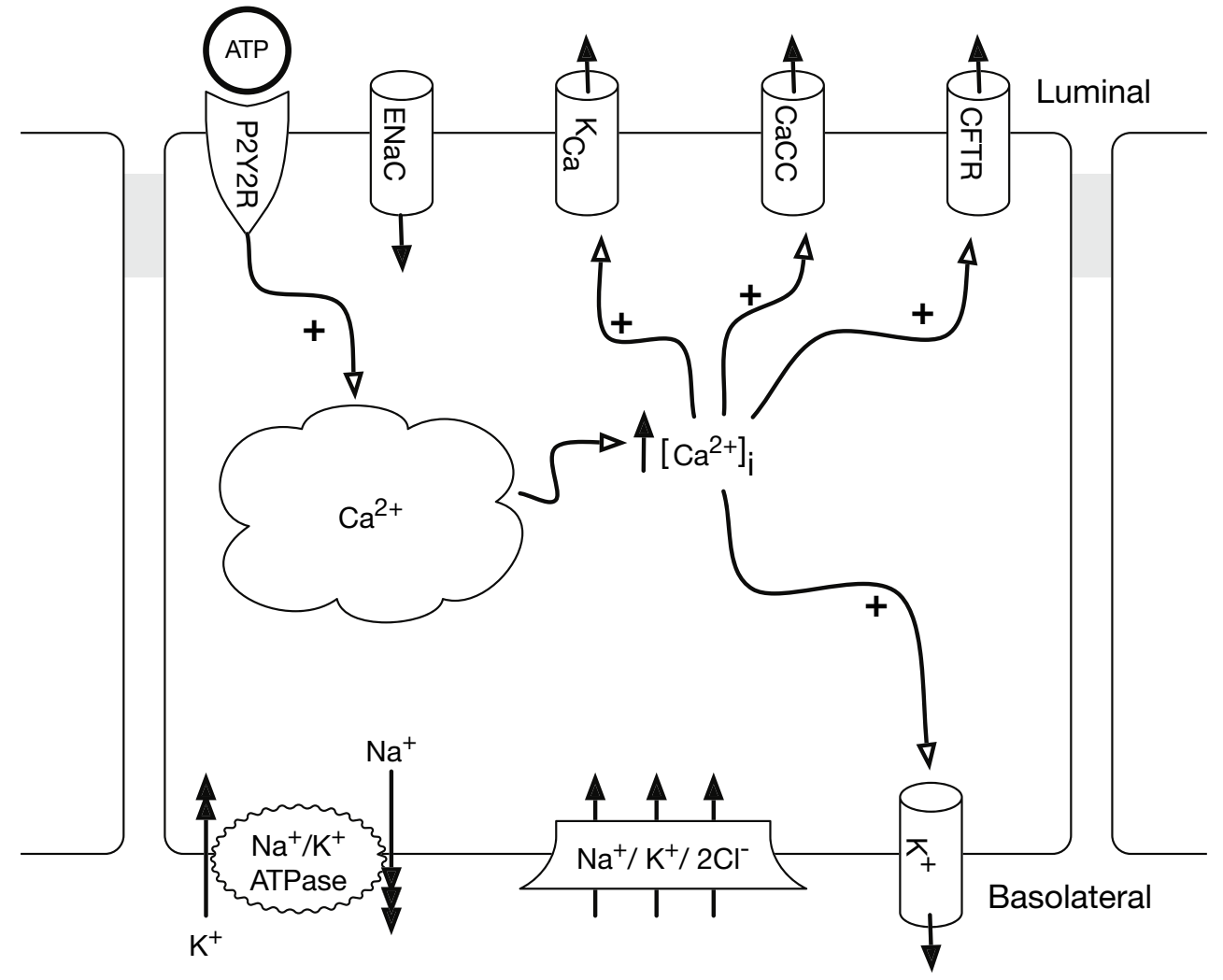

study in comparison to ATPe, suggests that this may be a valid hypothesis (Fig. 5a).

P2 receptor association of the Isc response was verified by demonstrating the inhibitory effect of suramin pretreatment (Fig. 5b). A P2Y agonist potency profile of ATP $=$ UTP $>$ ADP was generated for the apical membrane, suggesting the involvement of the P2YR2 subtype of purinoceptor. A P2X potency profile of ATP $=2$ MeSATP $>$ alpha, beta-meATP $>$ BzATP was also generated for the apical membrane. Elucidation of the specific receptor subtypes involved is difficult and significantly hindered by the general absence of high affinity agonists and antagonists. For example, BzATP has been shown to be a potent agonist at P2XR7, [24] while also effective at P2XR1 and P2XR4 [25]. Similarly, alpha,beta-meATP, which is a potent agonist at P2XR1 and P2XR3 [24] is also an agonist at P2XR5 receptors [26]. Even though multiple P2X receptors are likely to be present in the apical membrane of bovine oviduct epithelial cells (BOEC), cross-desensitization with equimolar UTP, together with the lack of cross-desensitization to the P2X agonist alpha,beta-meATP suggests that ATPe is most likely exerting its effects on the oviduct via a $\mathrm{P} 2 \mathrm{Y}$ receptor subtype and not a $\mathrm{P} 2 \mathrm{X}$ receptor subtype.

Both membrane domains of polarized epithelial oviduct monolayers can respond to stimulation with ATPe; however, increased efficacy of anion secretion was elicited from the apical face. Novel cross-talk between the apical and basolateral purinergic receptor activation also exists in bovine oviduct epithelial cells (Fig. 6). The mechanism involved in the down-regulation of a contralateral nucleotide challenge is unknown. Given that a sustained increase in current is only observed in response to apical ATPe, and not basolateral ATPe, it is possible that activation of this current inhibits subsequent responses to basolateral ATPe. The transient nature of calcium-dependent responses has been suggested to be related in part to the concomitant generation of signals, rendering the epithelia refractory to activation by a second calcium dependent agonist. The inositol phosphate messenger, IP4, can mediate this inhibitory pathway [27] and appears to target an apical calcium-activated chloride channel in a number of epithelial cell types [28, 29]. A similar effect has been observed by Smitham and Barrett, [30] in intestinal epithelial cells. Smitham and co-workers suggested that the inhibition of apical UTP-induced chloride secretion by basolateral ATP in their study was mediated by the increased levels of IP4 generated by basolateral UTP.

The present study clearly identifies key elements and emphasizes the purinergic regulation of ion transport on the apical surface of oviduct epithelia cells. The effect of ATPe on bicarbonate secretion in the oviduct is highly significant given the importance of this anion in a number of reproductive events. Although the exact mechanisms involved remain to be elucidated, CFTR is a likely candidate. Chan et al. [18] reported a critical role for CFTR in uterine bicarbonate 
secretion and the fertilizing capacity of sperm. Co-culture of sperm with CFTR antisense-treated endometrial cells or $\mathrm{HCO}_{3}{ }^{-}$secretion-defective $\mathrm{CF}$ epithelial cells resulted in reduced sperm capacitation and egg-fertilizing ability. Thus, since sperm capacitation in vivo occurs in the oviduct it is likely that CFTR may play a similar role in $\mathrm{HCO}_{3}{ }^{-}$secretion and the fertilizing capacity of sperm in the oviduct with ATPe acting as a potentially important regulator. This data allows us to propose a model for the regulation of ion transport by apical ATPe in the oviduct (Fig. 7).

Funding This work was partly funded by the Millennium Research Fund, National University of Ireland, Galway.

\section{Compliance with ethical standards}

Conflict of interest All Authors declare no conflicts of interest.

Ethical approval All applicable international, national, and/or institutional guidelines for the care and use of animals were followed.

\section{References}

1. Keating N, Quinlan LR (2008) Effect of basolateral adenosine triphosphate on chloride secretion by bovine oviductal epithelium. Biol Reprod 78:1119-1126. https://doi.org/10.1095/biolr eprod.107.065508

2. Borland RM, Biggers JD, Lechene CP, Taymor ML (1980) Elemental composition of fluid in the human Fallopian-tube. J Reprod Fertil 58:479-482

3. Tay JI, Rutherford AJ, Killick SR et al (1997) Human tubal fluid: production, nutrient composition and response to adrenergic agents. Hum Reprod 12:2451-2456

4. Keating N, Quinlan LR (2012) Small conductance potassium channels drive ATP-activated chloride secretion in the oviduct. Am J Physiol Cell Physiol 302:C100-C109. https://doi. org/10.1152/ajpcell.00503.2010

5. Leese HJ, Tay JI, Reischl J, Downing SJ (2001) Formation of Fallopian tubal fluid: role of a neglected epithelium. Reproduction 121:339-346

6. Dickens CJ, Comer MT, Southgate J, Leese HJ (1996) Human Fallopian tubal epithelial cells in vitro: establishment of polarity and potential role of intracellular calcium and extracellular ATP in fluid secretion. Hum Reprod 11:212-217

7. Dickens CJ, Leese HJ (1994) The regulation of rabbit oviduct fluid formation. J Reprod Fertil 100:577-581

8. Ajonuma LC, Ng EHY, Chow PH et al (2005) Increased cystic fibrosis transmembrane conductance regulator (CFTR) expression in the human hydrosalpinx. Hum Reprod 20:1228-1234. https:// doi.org/10.1093/humrep/deh773

9. Glasser SR, Mulholland J (1993) Receptivity is a polarity dependent special function of hormonally regulated uterine epithelialcells. Microsc Res Tech 25:106-120. https://doi.org/10.1002/ jemt.1070250204

10. Barrett KE (1993) Positive and negative regulation of chloride secretion in T84 cells. Am J Physiol Regul Integr Comp Physiol 265:859-868

11. Aliagas E, Torrejón-Escribano B, Lavoie EG et al (2010) Changes in expression and activity levels of ecto-5'nucleotidase/CD73 along the mouse female estrous cycle. Acta Physiol 199:191-197. https://doi.org/10.111 1/j.1748-1716.2010.02095.x

12. Praetorius HA, Leipziger J (2010) Intrarenal purinergic signaling in the control of renal tubular transport. Annu Rev Physiol 72:377-393. https://doi.org/10.1146/annurev-physiol-02190 9-135825

13. Burnstock $\mathrm{G}$ (2006) Pathophysiology and therapeutic potential of purinergic signaling. Pharmacol Rev 58:58-86. https://doi. org/10.1124/pr.58.1.5

14. Bucheimer RE, Linden J (2004) Purinergic regulation of epithelial transport. J Physiol 555:311-321. https://doi.org/10.1113/ jphysiol.2003.056697

15. Yu H, Bianchi B, Metzger R, et al (1999) Lack of specificity of [35S]-ATP $\gamma \mathrm{S}$ and [35S]-ADP $\beta S$ as radioligands for ionotropic and metabotropic P2 receptor binding. Drug Development Research 48:84-93. https://doi.org/10.1002/ (sici) 1098-2299(199910)48:2<84:aid-ddr6>3.3.co;2-w

16. Cuffe JE, Bielfeld-Ackermann A, Thomas J et al (2000) ATP stimulates $\mathrm{Cl}^{-}$secretion and reduces amiloride-sensitive $\mathrm{Na}^{+}$absorption in M-1 mouse cortical collecting duct cells. J Physiol (Lond) 524:77-90. https://doi.org/10.1111/j.1469-7793.2000.00077.x

17. Palmer-Densmore M, Deachapunya C, Kannan M, O'Grady SM (2002) UTP-dependent inhibition of $\mathrm{Na}^{+}$absorption requires activation of PKC in endometrial epithelial cells. J Gen Physiol 120:897-906. https://doi.org/10.1085/jgp.20028608

18. Chan HC, Shi QX, Zhou CX et al (2006) Critical role of CFTR in uterine bicarbonate secretion and the fertilizing capacity of sperm. Mol Cell Endocrinol 250:106-113. https://doi. org/10.1016/j.mce.2005.12.032

19. Wang XF, Zhou CX, Shi QX et al (2003) Involvement of CFTR in uterine bicarbonate secretion and the fertilizing capacity of sperm. Nat Cell Biol 5:902-906. https://doi.org/10.1038/ncb1047

20. Chan LN, Wang XF, Tsang LL, Chan HC (2000) Pyrimidinoceptors-mediated activation of $\mathrm{Ca}(2+)$-dependent $\mathrm{Cl}(-)$ conductance in mouse endometrial epithelial cells. Biochimica et Biophysica Acta (BBA) - molecular. Cell Res 1497:261-270. https://doi. org/10.1016/S0167-4889(00)00057-4

21. Zsembery A, Sitter G, Jessner W et al (2000) Correction of defective CFTR function in bile ductular cells from a patient with cystic fibrosis. J Hepatol 32:208-209

22. Clarke LL, Harline MC, Gawenis LR et al (2000) Extracellular UTP stimulates electrogenic bicarbonate secretion across CFTR knockout gallbladder epithelium. Am J Physiol 279:G132-G138. https://doi.org/10.1152/ajpgi.2000.279.1.G132

23. Al-Nakkash L, Cotton CU (1997) Bovine pancreatic duct cells express cAMP- and $\mathrm{Ca}(2+)$-activated apical membrane $\mathrm{Cl}-$ conductances. American Journal of Physiology-Gastrointestinal and Liver. Physiology 273:G204-G216. https://doi.org/10.1152/ajpgi .1997.273.1.G204

24. Ralevic V, Burnstock G (1998) Receptors for purines and pyrimidines. Pharmacol Rev 50:413-492

25. Bianchi BR, Lynch KJ, Touma E et al (1999) Pharmacological characterization of recombinant human and rat $\mathrm{P} 2 \mathrm{X}$ receptor subtypes. Eur J Pharmacol 376:127-138. https://doi.org/10.1016/ S0014-2999(99)00350-7

26. Bo X, Jiang L-H, Wilson HL et al (2003) Pharmacological and biophysical properties of the human P2X5 receptor. Mol Pharmacol 63:1407-1416. https://doi.org/10.1124/mol.63.6.1407

27. Barrett KE, Smitham J, Traynor-Kaplan A, Uribe JM (1998) Inhibition of $\mathrm{Ca}^{2+}$-dependent $\mathrm{Cl}^{-}$secretion in T84 cells: membrane target(s) of inhibition is agonist specific. Am J Physiol 274:C958C965. https://doi.org/10.1152/ajpcell.1998.274.4.C958

28. Carew MA, Yang XN, Schultz C, Shears SB (2000) Myo-inositol 3,4,5,6-tetrakisphosphate inhibits an apical calcium-activated chloride conductance in polarized monolayers of a cystic fibrosis 
cell line. J Biol Chem 275:26906-26913. https://doi.org/10.1074/ jbc.M002316200

29. Ho M, Kaetzel MA, Armstrong DL, Shears SB (2001) Regulation of a human chloride channel-a paradigm for integrating input from calcium, type II calmodulin-dependent protein kinase, and inositol 3,4,5,6-tetrakisphosphate. J Biol Chem 276:18673-18680. https://doi.org/10.1074/jbc.M101128200
30. Smitham JE, Barrett KE (1998) Differential effects of uridine triphosphate on intestinal chloride secretion depending on side of addition: implications for cystic fibrosis therapy. YGAST 114:A417-A418. https://doi.org/10.1016/S0016-5085(98)81690 $-9$ 